\title{
HEAT CRAMPS. A CLINICAL AND CHEMICAL STUDY
}

\author{
By JOHN H. TALBOTT AND JOST MICHELSEN
}

(From the Fatigue Laboratory, Morgan Hall, Harvard University, Boston, and the Six Companies Hospital, Boulder City, Nevada)

(Received for publication December 15, 1932)

The regulation of the interchange of water and salt in the body is a delicate and very precise mechanism. Haldane and Priestley (1) found no change in the percentage of hemoglobin in the blood after ingestion of large amounts of water plus salt. Later Priestley (2) reported a diminution in the electrical conductivity of the serum following an increased water intake and an increase of conductivity after ingestion of salt solution. Crawford (3), Adolph (4) and others confirm these findings. Because of experimental difficulties fewer data are available concerning a restricted intake of these constituents in normal men. The increased output of water and salt, however, especially in urine, sweat and vomitus, has been studied extensively. Gamble and Ross (5) found a marked reduction in body weight in dogs after experimental pyloric obstruction. This loss of weight and inability to assimilate ingesta from vomiting was essentially referable to a loss of water plus sodium and chloride ions. Sweating is another mechanism by which salt and water are lost from the body. In a temperate climate this salt loss is small, even in heavy work, and is not responsible for a fall of the salt level of the blood serum (6). In a hot climate, however, sweating may reach a magnitude sufficient to alter various constituents of the blood during a work period of several hours duration (7). If this changed composition of blood reaches sufficient magnitude, then a break-down of some function of the living organism may be expected.

Clinically the failure of the human organism to cope with a high environmental temperature is generally associated with the conditions known as sun stroke, heat stroke and heat exhaustion. There is another malady less well known, but nevertheless definite in its characteristics, that is frequently seen in workers in extreme heat. This is known as heat cramps. In 1904 Edsall (8) described two cases of painful cramps admitted to the hospital and later (9) attributed them to exposure to intense heat. Miners and firemen frequently report off duty because of severe muscle cramps when working in high temperatures. This malady has been adequately described and satisfactorily named but the cause has not been clearly defined. This communication is a study of several cases of heat cramps with a simple hypothesis for their origin. 
During the summer of 1932 members of this laboratory were investigating the physiological and pathological effects of high temperature upon the living organism. Boulder City, Nevada, as the center of operations for the construction of Hoover Dam, offered unusual opportunities for this study. This city, only seven miles from the site of Hoover Dam, is situated in the Colorado River Basin Desert. There were approximately 2500 men working on the Dam who lived in Boulder City during the recent summer. ${ }^{1}$ Figure 1 gives the daily maximum temperatures in

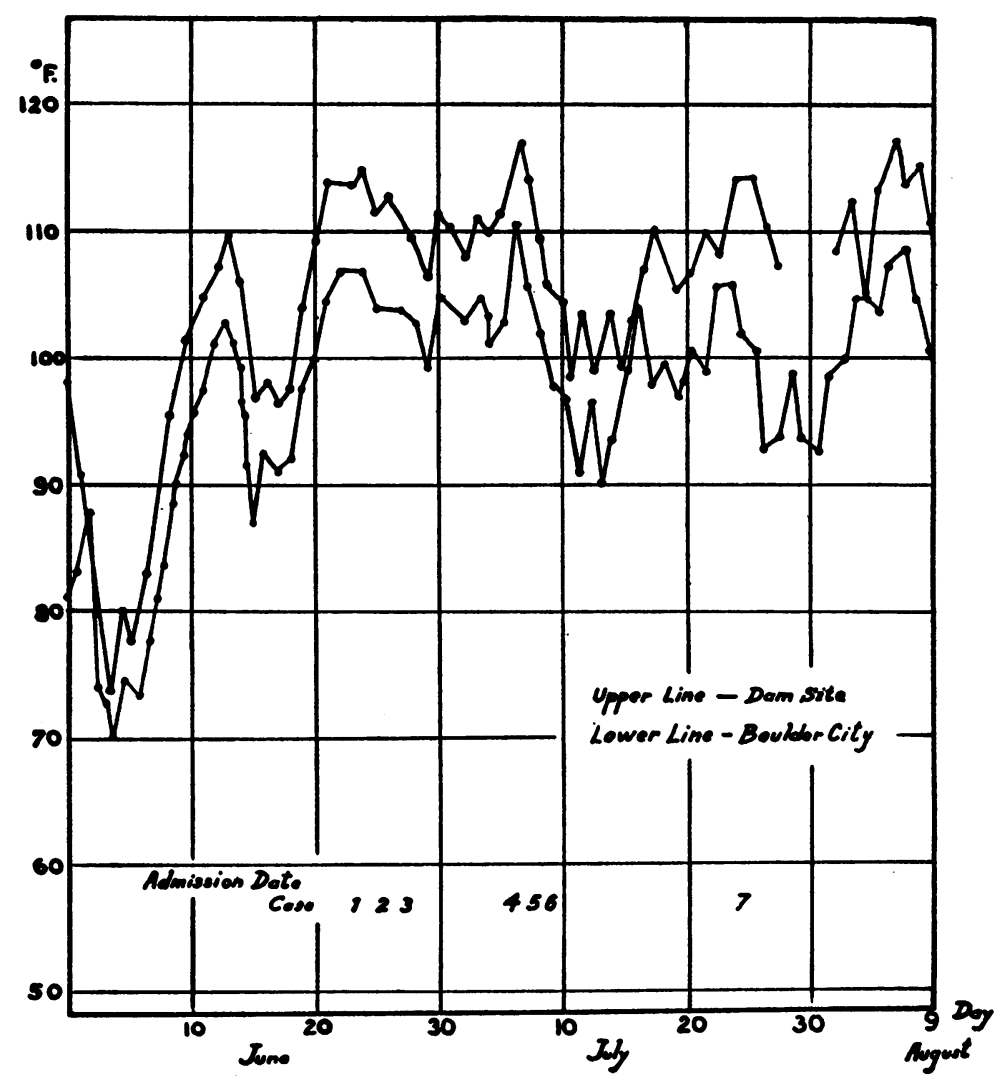

Fig. 1. Maximum Daily Temperature Observations During the Summer of 1932

Boulder City and at the Dam site during this period. The admission dates for the cases discussed are noted on this figure. There were roughly four hot spells of 4 to 5 days each, and during these periods of heat all of

${ }^{1}$ The employees of the Six Companies Construction Company were cared for at their own Hospital. This is a modern 60 -bed hospital, well equipped to care for medical and surgical cases, located in Boulder City. The authors were given a "free hand" in the diagnosis, treatment and investigation of all suspected and verified cases suffering from the ill effects of heat. 
the cases were admitted to the hospital. All of the suspected heat cases were seen within 15 minutes after admission and within 45 minutes after leaving the Dam. No known medication was given before they were seen by us. Forty cc. of venous blood was drawn shortly after we saw the patient, and following this a history was taken and physical examination was done. Thus the significant observations were completed before hypodermic, subcutaneous or intravenous therapy was begun.

The hospital cases admitted because of the ill effects of heat were few in number when a comparison is made with the preceding summer. While accurate statistics are not available concerning the mild and moderate cases suffering from heat, there are 17 cases in the insurance records in which death was attributed to heat from May to October, 1931. There were no deaths from heat in the summer of 1932, and according to sources considered to be reliable the number of mild and moderate heat cases was markedly below that for the summer of 1931 . Greatly improved living quarters, milder temperature, abundance of cooled drinking water and acclimatization were probable factors in this reduction.

There are seven cases described in this paper. Five of these were suffering from heat cramps and two from heat exhaustion. All of the cases of heat cramps admitted to the hospital during our stay in Boulder City are included.

\section{METHODS}

The methods employed for the determination of all of the urinary constituents and the majority of the blood constituents are given in a previous paper (6). The chlorides of the serum and cells were determined according to Wilson and Ball (10). The micro method of Folin and Malmros (11) was used for blood sugar. The total fixed base of the serum was determined after Van Slyke et al. (12). The morphology of the blood was studied in the accepted clinical fashion.

Heparin was added as an anticoagulant to the drawn blood. Blood for estimation of lactic acid, sugar and formed elements was removed at once. The remainder, about $35 \mathrm{cc}$., was equilibrated at $37.5^{\circ}$ in a water bath at the approximate value $\mathrm{PCO}_{2}=40 \mathrm{~mm}$. Hg. After 15 minutes equilibration, blood for measurements of oxygen capacity and $\mathrm{CO}_{2}$ content was removed. The remaining whole blood was then centrifuged for three 20-minute periods. Calculation of cell volume at infinite time was then possible according to Hirota's method (13). The various serum determinations were performed on the separated plasma and the cell water and cell chloride on the separated cells.

\section{RESULTS}

In no instance was arterial blood secured and the equilibration of venous blood was carried out under tensions of carbon dioxide that varied somewhat in the series. Thus Table I of experimental observations is supplemented by Table II, which permits a ready and more exact comparison of the acid-base equilibrium in the serum. The original data may be recalculated assuming a constant value for one of the several 


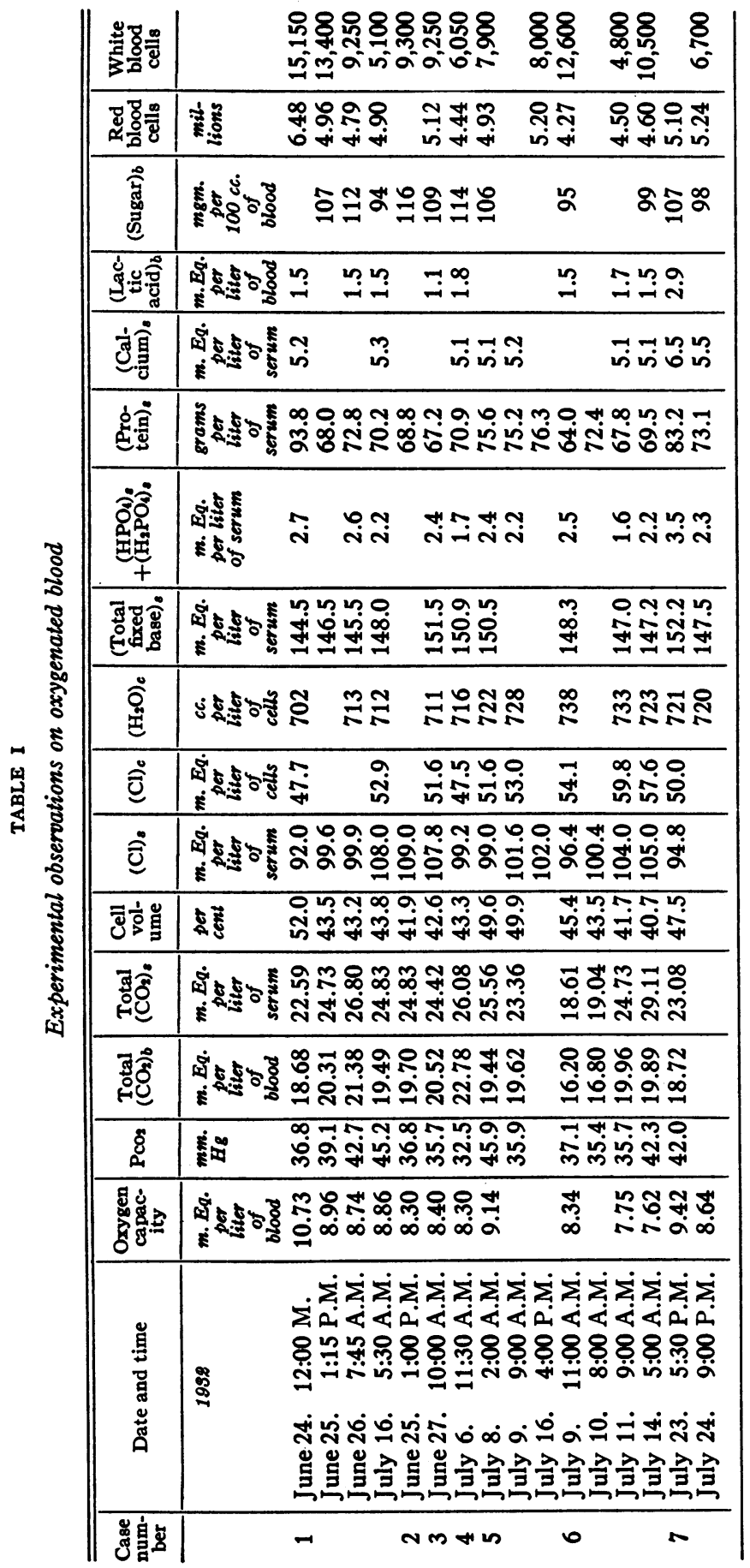


variables. $\mathrm{pH}_{s}=7.45$ has been arbitrarily selected in the construction of Table II. This treatment has certain disadvantages; nevertheless its use is probably justified.

TABLE II

Electrolytes of true plasma and $\mathrm{r}_{\mathrm{Cl}}$ at $\mathrm{pH},=7.45$

(Concentrations are expressed in m. Eq. per liter of serum excepting $r_{\mathrm{Cl}}$ )

\begin{tabular}{|c|c|c|c|c|c|c|c|c|c|}
\hline $\begin{array}{c}\text { Case } \\
\text { number }\end{array}$ & Date & $\left(\mathrm{HCO}_{3}\right)^{-}$ & (Lac- & $(\mathrm{Cl})^{-}$ & $\begin{array}{r}\left(\mathrm{HPO}_{4}\right)^{--}- \\
+\left(\mathrm{H}_{2} \mathrm{PO}_{4}\right)^{-}\end{array}$ & $\begin{array}{c}\text { (Pro- } \\
\text { teinate)- }\end{array}$ & I Anions & $\begin{array}{l}\text { Total } \\
\text { base }\end{array}$ & $r_{\mathrm{Cl}}$ \\
\hline \multirow{4}{*}{1} & $19 s 2$ & & & & & & & & \multirow{3}{*}{.65} \\
\hline & June 24 & 21.12 & 1.5 & 92.7 & 2.69 & 23.1 & 141.1 & 146.1 & \\
\hline & June 26 & 25.10 & 1.5 & 100.5 & 2.58 & 17.9 & 147.6 & 146.3 & \\
\hline & July 16 & 22.98 & 1.5 & 109.4 & 2.18 & 17.3 & 153.3 & 148.8 & .62 \\
\hline 3 & June 27 & 23.13 & 1.1 & 108.2 & 2.44 & 16.5 & 151.4 & 151.8 & .62 \\
\hline 4 & July 6 & 25.27 & 1.8 & 98.7 & 1.72 & 17.5 & 145.0 & 150.6 & .62 \\
\hline \multirow[t]{2}{*}{5} & July 8 & 23.52 & 1.5 & 99.0 & 2.39 & 18.6 & 145.0 & 151.5 & .66 \\
\hline & July 9 & 21.52 & 1.5 & 102.3 & 2.17 & 18.8 & 146.3 & & .65 \\
\hline \multirow[t]{3}{*}{6} & July 9 & 16.52 & 1.5 & 98.4 & 2.55 & 15.8 & 134.8 & 149.6 & .66 \\
\hline & July 11 & 22.70 & 1.7 & 105.6 & 1.61 & 16.7 & 148.3 & 148.1 & .71 \\
\hline & July 14 & 21.38 & 1.5 & 106.5 & 2.18 & 17.1 & 148.7 & 148.5 & .68 \\
\hline 7 & July 23 & 21.18 & 2.9 & 96.1 & 3.55 & 20.5 & 144.3 & 153.2 & .65 \\
\hline
\end{tabular}

It is possible to calculate very accurately the total carbon dioxide of whole blood at $\mathrm{pH}_{s}=7.45$ with knowledge of the oxygen capacity and the partial pressure of $\mathrm{CO}_{2}$ during equilibration (14). The spread between total $\mathrm{CO}_{2}$ of whole blood and true plasma was assumed to be the same for a given specimen of blood at the observed $\mathrm{pH}$, and at $\mathrm{pH}_{\mathbf{c}}=\mathbf{7 . 4 5}$. Total $\mathrm{CO}_{2}$ of true plasma at $\mathrm{pH}_{8}=7.45$ was calculated on this basis.

Values for $\mathrm{pH}$ are derived from the equation

where

$$
\mathrm{pH}_{\mathrm{s}}=\mathrm{pK}_{\mathrm{s}}+\log \left(\mathrm{BHCO}_{3}\right)_{\odot}-\log \left(\mathrm{H}_{2} \mathrm{CO}_{3}\right)_{\text {, }}
$$

$$
\mathrm{pK}_{\varepsilon}=6.10 \text {, }
$$

and

m. Eq. $\left(\mathrm{H}_{2} \mathrm{CO}_{3}\right)_{8}=0.031\left(\mathrm{H}_{2} \mathrm{O}\right)_{\&} \mathrm{PCO}_{2}$,

$$
\left(\mathrm{BHCO}_{3}\right)_{8}=\left(\text { total } \mathrm{CO}_{2}\right)_{8}-\left(\mathrm{H}_{2} \mathrm{CO}_{3}\right)_{8} \text {. }
$$

Base bound by protein is calculated according to Van Slyke, Hastings, Hiller and Sendroy (15).

where

$$
\text { m. Eq. (BP) })_{s}=0.104(\mathrm{P}) .\left(\mathrm{pH}_{s}-5.08\right) \text {, }
$$

and

$$
(\mathrm{P})_{\mathrm{a}}=\text { grams of protein per liter of serum }
$$

$$
\mathrm{pH}_{s}=7.45 \text {. }
$$

Values for serum volume and serum and cell chloride were corrected to $\mathrm{pH}_{\mathrm{s}}=7.45$ by reference to unpublished observations on dog's blood.

The following formulae were employed. 


$$
\begin{aligned}
& \mathrm{V}_{\text {c cor. }}=\mathrm{V}_{\text {cobs. }}+4.0\left(\mathrm{pH}_{\text {s obs. }}-7.45\right), \\
& \mathrm{Cl}_{\text {s cor. }}=\mathrm{Cl}_{\text {s obs. }}-13.3\left(\mathrm{pH}_{\text {s obs. }}-7.45\right), \\
& \mathrm{Cl}_{c_{\text {cor. }}}=\mathrm{Cl}_{\text {cobs. }}+20.0\left(\mathrm{pH}_{\text {s obs. }}-7.45\right)
\end{aligned}
$$

The shift in serum volume and chloride for dog's blood within the physiological range is probably close enough to that of man to introduce no significant error in its use. Lactate of serum is calculated from its concentration in whole blood, assuming the concentration in cells and serum to be equal.

The expression $\Sigma$ anions represents the corrected sum of the anions, which, if all anions were accounted for, should be approximately equal to the corresponding value for total base. Inspection of these values shows a striking difference between the blood on admission and after recovery. A marked discrepancy between total anions and cations is found only in the admission blood. Values for $\left(\mathrm{HCO}_{3}\right)^{-}$, except in Case 6 , are only slightly below an average normal of $24 \mathrm{~m}$. Eq. The lactate and inorganic phosphate of the serum are only slightly elevated, except in Case 7, where both values are about twice the normal ones. The proteinate ions are considerably increased because of a concentration of the blood proteins related to the degree of dehydration. Shifts of these four electrolytes of this magnitude and direction are frequently seen in a physiological state no more abnormal than that accompanying moderate exercise. It is our impression that the distribution of the chloride ion is regulated by a mechanism more resistant to change, and that an elevation or depletion of the blood chloride is seen only in disease. Thus the low values for chlorides seem to us most significant of all.

In all cases the blood taken on the second day of hospitalization after treatment had begun shows chloride values only slightly below normal. This significant rise in serum chloride coincided clinically with relief from cramps. Cases 2 and 3, who did not complain of cramps, had normal chloride values. The total base of the serum was low on admission and in Cases 1 and 6 did not reach the normal value of $152 \mathrm{~m}$. Eq. during recovery.

The concentration of red blood corpuscles corresponds closely to the oxygen capacity and cell volume. Calculation of the cell hemoglobin gives an average value of $19.6 \mathrm{~m}$. Eq. per liter of cells. This is slightly below the value of 20.3 given by Dill (16) for 7 normal subjects. There was some tendency for the white cells of the blood to be elevated with only slight increases in the polymorphonuclear percentage. All of the patients with elevated white counts had normal rectal temperatures.

Table III contains data concerning water balance. The fluid intake, high as it may seem, is probably considerably below the average daily intake for workmen during the hot periods. The values for salt intake 
JOHN H. TALBOTT AND JOST MICHELSEN

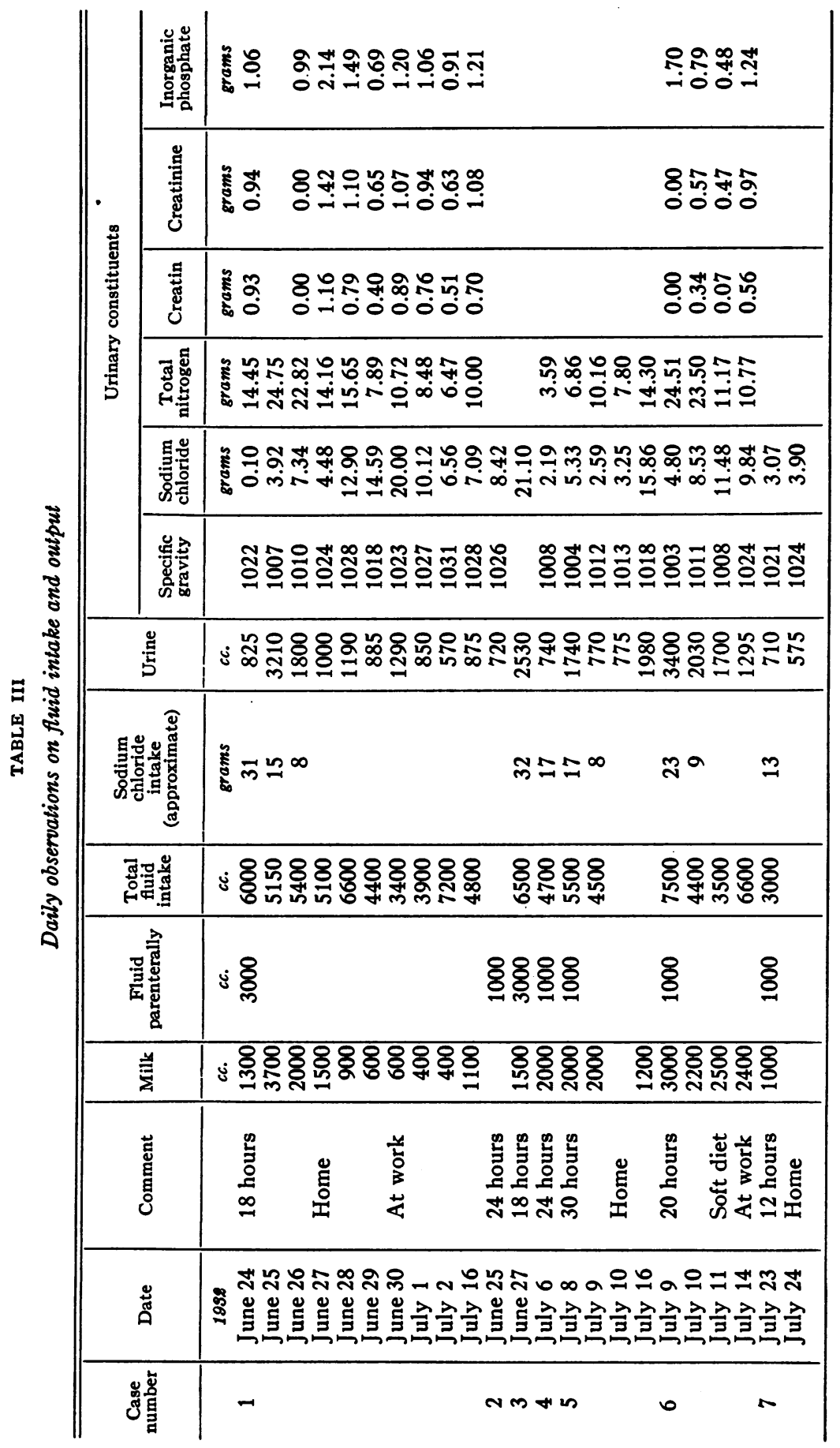


are only approximate but show in a striking degree the retention of salt ${ }^{2}$ by the body early in recovery. This was most marked in Case 1 where the intake of 45 grams of salt in 42 hours was accompanied by a urinary excretion of only 4 grams. Only a small amount of the salt not accounted for was lost in the stools and by sweating; the remainder was retained by the body. Values for total nitrogen in the urine are high for the first two days of observation. In an unpublished study of the healthy workmen at the Dam no such increase was found in any of the 24-hour urine specimens. It seems unlikely that the high nitrogen excretion can be attributed to exercise, to the high environmental temperature or to elevated body temperature. Increased destruction of muscle protein accompanying the cramps may be the source of some of the additional nitrogen. ${ }^{3}$ The utilization of tissue protein for fuel is probably responsible for most of the increase.

\section{CLINICAL DISCUSSION}

The characteristics that distinguish heat cramps from other varieties of cramps are few. The past history may reveal a previous attack of cramps while working in a high temperature. J. C. (Case 7) was the only patient in our series that admitted having had heat cramps previously. Individual variation in susceptibility is undoubtedly important. This response is intimately related to the phenomenon of acclimatization to the heat. Adequate proof of acclimatization is not at present available but certain considerations strongly suggest this. Acclimatization seems to be complete after the 3rd to 5th day. It is our belief that any given individual is more resistant to cramps after this 5-day period, other factors being equal. Moss (17) noted that colliers acclimatized to a high temperature lost twice as much sweat under the same conditions as unacclimatized subjects. Our observations (7) do not agree with these findings.

There may be a prodromal period of 1 to 3 days before the onset of acute symptoms. During this time the salt intake may be exceeded by the salt excretion. An alcoholic bout with diminished intake of food and salt may be followed by sufficient gastric irritation and vomiting to lower appreciably the salt level of the body. In Case 1 the 3-day prodromal period was preceded by an alcoholic bout, the severity and importance of which could not be ascertained. Vomiting with loss of electrolytes preceded the muscle cramps in Cases 1, 5 and 6, and nausea was a symptom in Case 7 as well. Diarrhea may be a symptom but was not noted in

${ }^{2}$ In most instances the use of the word salt implies sodium chloride, as based on chloride determinations.

${ }^{3}$ This process is similar to that observed by Morawitz in cases of nonnephritic uremia with hypochloremia. Morawitz, P., and Schloss, M., Klin. Wchnschr., 1932, xi, 1628. 'Extrarenale' Albuminurie und Urämie. 
any of our cases of cramps. There was a prevailing impression that profuse and explosive diarrhea was an accompaniment of most of the severe heat cases in the summer of 1931 . No figures are available showing the incidence of diarrhea in uncomplicated heat cramps and in other ill effects of heat. It is interesting to note that cases of cholera as described in the literature have muscle cramps associated with prolonged diarrhea. As in heat cramps the vomiting and diarrhea may seriously deplete the salt in the body.

The presenting symptom is generally pain in various groups of muscles which prevents the subject from continuing work. Tingling in the fingers and toes may precede or accompany the cramps. Edsall (9) observed extreme irritability and fibrillary twitchings of the involved muscles in his patients with heat cramps. Deep or superficial palpation produced pain. In contrast in none of our cases were there fibrillary twitchings nor did palpation produce pain. However, active motion of the affected muscles was painful in our most severe cases.

The predilection of certain groups of smooth and striated muscles for cramps is worth noting. The muscles of the calf and the flexors of the forearms were the commonest sites. The muscles of the abdominal wall were also affected in some instances quite apart from the smooth muscle of the gut. It is our belief that the vomiting and diarrhea may be referable to irritation of the smooth muscle by a process similar to that causing cramps in striated muscle. The effect of diminished blood chloride upon the heart muscle is an interesting problem for speculation. Dr. D. B. Dill suggested to us that the symptoms of Case 4 might be referred to such salt depletion. This patient came into the hospital with symptoms in some respects resembling those of coronary occlusion. His past cardiac history was not important. The physical examination was negative. His serum chlorides were below normal and he responded in a typical fashion to intravenous saline. The retention of salt during the following 24 hours is further proof of the lowered salt level of his body. The hospital does not have an electrocardiograph and no record was taken.

The relation of heat cramps to heat exhaustion or heat stroke has not been clearly defined. In common with heat stroke or exhaustion is the exposure to a high temperature and the resultant loss of large volumes of sweat. Haldane (18) found a maximum loss of $5 \frac{1}{2}$ pounds per hour in seasoned colliers at work, and a much smaller loss of sweat in unacclimatized workers. That the amount of sweating is a function of external temperature rather than duration of exposure was substantiated by experiments of Hunt (19). In a Turkish bath he found that the sweat loss was about 2 pounds per hour when the temperature was between $60^{\circ}$ and $80^{\circ} \mathrm{C}$. Sweating was as free at the end of 3 hours as it was early in the experiment. This agrees with observations on ourselves during 
the summer. The comparison of heat stroke with cramps and with prostration reveals less similarity beyond this point. Clinical evidence against a common causal agent in heat stroke and heat cramps is afforded by the observation made by Willcox (20). He noted that the convulsions in heat stroke were made worse after intravenous saline injections. The opposite effect might be expected if the essential pathological process were a depletion of salt and water in the central nervous system. Cramp cases show only a slight elevation of body temperature. None of the cases in our series had a temperature above $101^{\circ} \mathrm{F}$. after admission to the hospital. It is conceivable, but unlikely, that the temperature was higher before admission. In 37 cases reported by Gauss (21) temperatures were subnormal in most of the subjects and were not elevated in any. Cases of heat exhaustion similarly have only a slightly elevated temperature. In contrast the heat stroke or heat hyperpyrexia patients run a fever frequently as high as $110^{\circ} \mathrm{F}$. with a correspondingly high pulse rate (Willcox, 20). The heart rate was as intimately related to body temperature, other factors being equal, in these cases as it had previously been found to be in hot-room experiments (22). In none of our cramp cases was the pulse over 90 . Restlessness and delirium were noted in one case only, Case 4, and he regained his mental equilibrium soon after admission to the hospital. In view of the number of cases diagnosed as sun stroke in the cities during the summer months, it is worth noting the absence of cases at Boulder City during the summer of 1932. Many of the men at work scaling the cliffs were exposed to the sun's rays for several hours each day. The shade temperature was frequently $45^{\circ}$ and the temperature of the rocks was $55^{\circ}$ to $60^{\circ} \mathrm{C}$. Each day between the hours of 10 and 12 in the morning one of us (J. H. T.) regularly played three hard sets of tennis in the direct sun without any head covering. The question of whether a healthy individual, accustomed to the heat for a few days, could succumb to sun stroke is an important one and not fully answered by the cases in the literature to date.

An important criterion in substantiating a diagnosis of heat cramps is the marked relief following parenteral injection of large amounts of normal salt solution. All of our cases in this series were free from symptoms within six hours after starting treatment.

In summary, then, a diagnosis of heat cramps may be made with the following conditions satisfied. (1) Exposure to a high temperature at work. (2) Rapid loss of salt in the sweat, that is not replaced. (3) Painful muscle cramps. (4) Diminished concentration of chloride and base in the blood and likewise in the body tissues. (5) Rapid amelioration of symptoms after therapy.

\section{PATHOGENESIS}

The pathogenesis of heat cramps has been variously assigned according to the period in which the several theories were advanced. In 1904 
Edsall (8) proposed, as the pathological process, acute degeneration in the muscle. Some time later an infectious agent was considered but this was never sufficiently proved. In recent years interest in this subject has been transferred to pathological physiology. In 1923 Haldane in his discussion of a paper by Moss (23) stated that he believed miners' cramps could be attributed to water poisoning. Haldane further says, "When a man is working his blood is shunted away from the kidneys and excretion of urine stops. If the kidneys were working normally they would excrete the excess of water and save the man from cramps." In consideration of our quantitative observations it is desirable to define water poisoning and to qualify the assertions concerning the excretion of urine.

The body tissues of patients with heat cramps contain hypotonic fluid as seen from Table II, but this is not from the excess of water, rather it is from the depletion of total base and chlorides. Likewise after the beginning of treatment, if salt and water are retained to make up the deficit, a gain in weight during recovery would be expected. If the fundamental process at fault were an increase of total body water, then the patients after the beginning of treatment would lose weight because of the diuretic action of salt and water. The facts observed in our cases that were weighed on admission and at discharge are as follows. Case 7 gained 3.0 pounds in the first 24 hours and Case 6 gained 7.0 pounds in 48 hours. In regard to kidney function it is our belief that the principal reason for low kidney excretion during working hours in a hot climate is peripheral dilatation of the capillaries for dissipation of heat, rather than a primary shut-down of the kidneys. Heller and Smirk (24) studying rabbits and rats demonstrated a water diuresis (diuresis following an elevated fluid intake) in the presence of depleted water reserves. There is no evidence that under the above conditions for man the kidneys are not capable of excreting any excess of water that may be taken in.

Haldane (23) predicted a lowering of the blood chlorides of 3 to 4 per cent as a possible accompaniment of heat cramps. In this series the mildest case showed a 2 per cent reduction in serum chlorides and the severest case a 10 per cent reduction below the accepted normal minimal value. Direct evidence is not at hand showing that the drop in the chloride level of the blood is followed by a similar depletion of the chloride in the intercellular spaces. It is generally assumed that the concentration of electrolytes in the serum and intercellular spaces is approximately equal. If these are the facts then a loss of water and salt from the blood is followed by a partial replacement from the tissues. In the condition under discussion there is a loss of salt and water from the body with a concomitant replacement of water only. If this major process is continued, irrespective of the secondary processes, there will eventually be a lowering of the chloride level below the normal range. It is our belief that when a critical level for the chlorides is reached in working.individuals 
muscle cramps will occur. It seems likely that the critical chloride level is a function of individual susceptibility, acclimatization and the length of the prodromal period.

\section{TREATMENT AND PREVENTION}

If the cause of heat cramps is essentially a loss of salt and water from the body tissues then treatment should provide for restoration. The most rapid replacement of salt and water is by means of intravenous saline solution. In our study only sodium chloride was used. A larger number of cases would have enabled us to use other salts in treatment. A control study with glucose infusions without salt would likewise have been desirable. In addition to the saline infusions an exclusive milk diet was given during the first 24 hours. This simple regime was highly satisfactory in all of the cases.

It is possible to prevent cramps by providing a daily supply of salt greater than that lost in the sweat. This amount may be determined by knowing the approximate amount of chloride excreted in a 24-hour urine specimen. In our experience less than 3 grams of salt per day in the urine does not provide for a satisfactory margin of safety. A high salt diet may be provided in a number of ways. Fresh cow's milk has an average salt concentration of about 0.3 per cent and this provides fluid as well as salt. The workers of South Metropolitan Gas Co., Great Britain (25), are given a saline drink of 0.012 per cent $\mathrm{KCl}$ and 0.018 per cent $\mathrm{NaCl}$. The number of heat cramp cases has been reduced since this regulation became effective. Salted drinking water (sodium chloride 0.25 to 1.0 per cent) has been used successfully in prevention of heat cramps among soldiers in the U. S. Army (26). Barley water and salted beer are used by certain local groups of colliers in England. It is possible that no salt need be taken between meals if the food is liberally salted at meal times. The necessary amount of salt to prevent cramps is a function of the individual's susceptibility and of the amount lost in the sweat at a given temperature.

The authors are deeply indebted to Dr. Wales Haas, Surgeon-in-Chief of the Six Companies Hospital, whose interest and cooperation made this work possible.

\section{SUMMARY}

This paper is a clinical description of five cases of heat cramps with a chemical study of the blood and urine. The hypothesis is advanced that the etiologic factor is a loss of base, chlorides and water from the body principally by way of the sweat glands without adequate replacement of the same. It is obvious that heat cramps is essentially an occupational disease and an industrial hazard is created by the association of hard work, high external temperatures and profuse sweating. 


\section{PROTOCOLS}

\section{Case 1}

Mr. J. F., a married white man of 42, entered the hospital on June 24, 1932, complaining of vomiting for 3 days and generalized muscle cramps for 12 hours.

Past history. Born in Nova Scotia, he has lived for the past 28 years in southwestern United States. He has never been in the tropics, has never noted any ill effects of heat, and prefers summer to winter. He perspires freely in a warm or hot environment and his skin tans easily. He came to Boulder City June 6, 1931, and has worked since that time in the Machine Shop situated on the edge of the city. He drank at least two quarts of milk daily during the first four months of his employment in the summer of 1931. In the fall his family moved to Las Vegas and he had virtually no milk after that time. $\mathrm{He}$ is a light meat eater, preferring fruits and vegetables and not especially addicted to the use of salt.

Present illness. Three days ago he began to vomit and, while the vomiting has diminished in severity, only a small amount of food and fluid has been tolerated during this period. Twelve hours ago cramps in the muscles of his legs first appeared and since then they have caused pain in his arms, hands, and abdominal wall. Change of position will generally bring on cramps in the parts moved, although deep pressure or palpation is not painful. He voided small amounts of urine twice during the twenty-four hours before admission. He has continued to perspire freely in spite of the low fluid intake.

Physical examination. Temperature, $99.6^{\circ} \mathrm{F}$; pulse, 88; respiration, 16; blood pressure, 130/84. The examination was essentially negative. The eye grounds were normal. Chvostek's and Trousseau's signs were negative. No fibrillary twitchings were seen.

Diagnosis. Heat cramps.

Treatment. He was given, during the first 24 hours, two hypodermoclyses of $1500 \mathrm{cc}$. of normal saline and was allowed to drink 3000 cc. of milk. He received no other food or fluids.

Course. The cramps ceased after 6 hours. He was sent home on the 3d day on a diet containing a minimum of one quart of milk daily. He resumed work the third day after discharge. Frequent follow-ups revealed no muscle soreness or cramps during the next two periods of hot weather.

\section{Case 2}

Mr. W. E. T., a single white male of 39 , entered the hospital June 25,1932 , complaining of right-sided headache and weakness in the legs of a few minutes duration.

Past history. He had served in the Navy during the World War and during the past year had several radical operations on his sinuses in the Veterans' Hospital in Los Angeles. He had been discharged from the hospital only one month when he was given a job on Hoover Dam. He had never lived or worked in a hot climate previously, and had worked only two hours the first day of employment when he stopped because of the above complaints. His daily intake of milk was over one quart.

Present illness. He had been working only two hours when he was forced to stop because of a severe right-sided headache and a weakness of his legs. $\mathrm{He}$ did not have any muscle cramps.

Physical examination. Temperature, $98.4^{\circ} \mathrm{F}$; pulse, 88 . The scars from the previous sinus operations were the only findings of note. The reflexes were not altered. 
Diagnosis. Mild heat prostration.

Treatment. He was given, during the 24 hours in the hospital, one hypodermoclysis of $1000 \mathrm{cc}$. and was allowed to drink milk ad libitum.

Course. He had no complaints after going to bed: His course through the summer was not followed as he did not return to work.

\section{Case 3}

Mr. H. P., a single white man of 42, entered the hospital June 27, 1932, complaining of vomiting and weakness for 12 hours.

Past history. He had lived from 1908 to 1910 in the Philippine Islands as a soldier in the United States Army. He had muscle cramps many times when working in the heat. The cramps were transitory and persisted no more than a few minutes with no therapy other than that of stopping work. He did not have any symptoms of heat stroke or heat exhaustion. From 1922 to 1928 he worked in a steel rolling mill in the United States and would have mild cramps at frequent intervals. He came to Boulder City in March, 1932, and has had mild muscle cramps three times since. These were in the calves of the legs or insteps of the feet. He has had no cramps for 3 weeks. His diet includes two glasses of milk daily. A warm climate is preferred to a cold one, his skin burns or tans depending upon the gradation of exposure to the sun and he perspires freely.

Present illness. The patient was aware of the relatively high atmospheric temperature on the day preceding admission. He perspired freely and was a ware of an increased water intake at work on this day. During the night he vomited several times and felt weak. He did not have muscle cramps.

Physical examination. Temperature, $98^{\circ} \mathrm{F}$; pulse, 88 . Slight tenderness in the epigastrium was the most important physical finding.

Diagnosis. Mild heat prostration.

Treatment. He was given, during the first 24 hours, two intravenous infusions of $1000 \mathrm{cc}$. of normal saline and was allowed a diet exclusively of milk.

Course. He did not vomit after admission to the hospital and was discharged the following day. A follow-up report 6 weeks later showed no symptoms since leaving the hospital.

\section{Case 4}

Mr. W. R., a divorced white man of 42 , entered the hospital on July 6 , 1932 , complaining of gas on the stomach and precordial pain radiating to the interscapular region.

Past history. Born in Kentucky, he has lived in the west for the past 10 years. For 22 years he has been employed as a miner at frequent intervals. In 1919 and 1920 he worked in the Texas oilfields in very hot weather without any ill effects directly attributed to the heat. Fifteen years ago he had a dizzy spell accompanied by slight cardiac pain. This was very mild and he has had no cardiac complaints at any time since. He came to Boulder City in March, 1932 , and since that time has worked in the tunnels.

Present illness. The past week-end he went on a mild alcoholic bout and returned to work the day of admission. Soon after starting work he had gas on his stomach followed by a short period of delirium. On partially recovering from the delirium he complained of mild precordial pain radiating to the interscapular region and fear of impending death. When he was brought to the hospital he was mildly delirious.

Physical examination. Temperature, $99.8^{\circ} \mathrm{F}$.; pulse, 98; respiration, 24; 
blood pressure, 132/84. There was mild dyspnea, precordial hyperesthesia, and the heart sounds were weak but no murmur or rub was heard.

Diagnosis. Heat cramps of myocardium?

Treatment. He was given, during the first 24 hours, an intravenous infusion of $1000 \mathrm{cc}$. of normal saline in 5 per cent glucose, and was allowed to drink 2000 cc. of milk. He received no other food or fluids.

Course. The patient was discharged after 24 hours and left Boulder City. There is no follow-up report available.

\section{Case 5}

Mr. R. F., a single white man of 33, entered the hospital on July 8, 1932, complaining of severe pain in the calves of his legs for 2 hours.

Past history. Born in Tennessee, he has lived the past $31 / 2$ years in the southwest. He has never complained of any ill effects of heat and prefers summer to winter. He drinks a great deal of water and perspires freely in the heat. Since coming to Boulder City 4 months ago he has worked in the tunnels. He drank 2 to 3 pints of milk daily until 2 weeks ago, at which time he stopped because of dislike for it. In recent years he has not added salt to his food at the table.

Present illness. Ten days ago he had a mild gastric upset from which he believes he has not fully recovered. He drank a small amount of beer over the holiday week-end. The night before admission he had slight tingling in the fingers and cramps in the leg muscles. About one hour after starting work on his second shift since the holidays, he became dizzy and vomited. The day was very warm and the profuse sweating was followed by consumption of large amounts of water. The patient complained of such severe pains in the legs that the ambulance attendant reported the case as traumatic.

Physical examination. Temperature, $101.0^{\circ} \mathrm{F}$.; pulse, 88 ; blood pressure, 128/82. A palpable spleen was the only abnormal finding. The reflexes were normal and no tenderness or fibrillary twitchings of the muscles were elicited.

Diagnosis. Mild heat cramps.

Treatment. A high milk diet was the only order.

Course. There was no recurrence of cramps and he was discharged after 3 days. He worked for 2 weeks without any symptoms, but decided he needed a rest so he went to his home in Tennessee for the remainder of the summer.

\section{Case 6}

Mr. G. D., a married white male of 38, entered the hospital on July 9, 1932, complaining of muscle cramps and vomiting for 3 hours.

Past history. Born in California, he has spent a long part of his life in a warm country. From 1920 to 1925 he was in Panama, while in recent years he has been working in Imperial and Death Valleys, California, without any ill effects of the heat. He came to Boulder City only 3 days ago and has worked outside on the Arizona Spillway for 2 days.

Present illness. The day before admission he felt badly at work, but a headache was the only specific complaint. He was slightly constipated and took a laxative with a good result some hours after. He obtained a good rest on the night before admission but felt badly on going to work. Muscle cramps in the arms, legs and abdomen forced him to stop work, and after vomiting 3 times he was sent to the hospital. On admission he complained of severe headache in addition to the cramps.

Physical examination. Temperature, $99.8^{\circ} \mathrm{F}$; pulse, 83 ; blood pressure, 118/68. The physical examination was negative. 
Diagnosis. Severe heat cramps.

Treatment. He was given an intravenous infusion of $1000 \mathrm{cc}$. of normal saline in 5 per cent glucose and was allowed a high milk diet.

Course. He had no complaints after 6 hours and next morning felt well enough to go back to work. He was discharged on the third day and returned to work the fourth day after admission. For 10 days he was symptom-free on a high salt and high milk diet. On the tenth day he fell while scaling a cliff, injuring his lumbar spine, and he did not return to work the remainder of the summer.

\section{Case 7}

Mr. J. C., a single white male of 38 , entered the hospital on July 23,1932 , complaining of cramps for 5 hours.

Past history. He was born in California and has lived for many years in a warm climate. From 1912 to 1914 he was stationed as a soldier in the Philippines and the only sickness there was dysentery. In 1929 he had mild muscle cramps while working in a hot climate. There was no recurrence. He came to Boulder City the day before admission and had only worked the first shift. In the heat he perspires very freely and has a large water intake.

Present illness. Three hours after commencing work he began to have muscle cramps, first in the left hand, spreading to the legs and abdominal muscles. He noted slight nausea but no vomiting or diarrhea. There was a slight frontal headache. His water intake was large in amount.

Physical examination. Temperature, $98.6^{\circ} \mathrm{F}$.; pulse, 84 ; blood pressure, $122 / 84$. There was no muscle tenderness and no twitchings were seen. The biceps reflex was bilaterally increased. The other reflexes were present and responded normally.

Diagnosis. Severe heat cramps.

Treatment. He was given, shortly after admission, an intravenous infusion of $1000 \mathrm{cc}$. of normal saline in 5 per cent glucose. His diet during the hospital stay was milk alone.

Course. The cramps ceased after 4 hours, and he was discharged the next morning. Two weeks after return to work he continued to be free of cramps.

\section{BIBLIOGRAPHY}

1. Haldane, J. S., and Priestley, J. G., J. Physiol., 1915-1916, i, 296. The Regulation of Excretion of Water by the Kidneys. I.

2. Priestley, J. G., J. Physiol., 1915-1916, i, 304. The Regulation of Excretion of Water by the Kidneys. II.

3. Crawford, J. H., Quart. J. Med., 1927, xxi, 71. Observations on the Excretion of Water and Chloride after their Oral Administration.

4. Adolph, E. F., J. Physiol., 1921, Iv, 114. The Regulation of the Water Content of the Human Organism.

5. Gamble, J. L., and Ross, S. G., J. Clin. Invest., 1924-1925, i, 403. The Factors in the Dehydration Following Pyloric Obstruction.

6. Talbott, J. H., Fölling, A., Henderson, L. J., Dill, D. B., Edwards, H. T., and Berggren, R. E. L., J. Biol. Chem., 1928, lxxviii, 445. Studies in Muscular Activity. V. Changes and Adaptations in Running.

7. Dill, D. B., Bock, A. V., and Edwards, H. T. (In Preparation). Mechanisms for Dissipation of Heat in Man and Dog.

8. Edsall, D. E., Am. J. M. Sc., 1904, cxxviii, 1003. Two Cases of Violent but Transitory Myokymia and Myotonia Apparently Due to Excessive Hot Weather. 
9. Edsall, D. E., J. A. M. A., 1908, li, 1969. A Disorder Due to Exposure to Intense Heat.

10. Wilson, D. W., and Ball, E. G., J. Biol. Chem., 1928, lxxix, 221. A Study of the Estimation of Chloride in Blood and Serum.

11. Folin, O., and Malmros, H., J. Biol. Chem., 1929, lxxxiii, 115. An Improved Form of Folin's Micro Method for Blood Sugar Determinations.

12. Van Slyke, D. D., Hiller, A., and Berthelsen, K. C., J. Biol. Chem., 1927, lxxiv, 659. A Gasometric Micro Method for Determination of Iodates and Sulphates, and Its Application to the Estimation of Total Base in Blood Serum.

13. Hirota, K., J. Biophys. (Japan), 1925, i, 233. The Determination of Cell Volume.

14. Henderson, L. J., Bock, A. V., Dill, D. B., and Edwards, H. T., J. Biol. Chem., 1930, lxxxvii, 181. Blood as a Physicochemical System. IX. The Carbon Dioxide Dissociation Curves of Oxygenated Human Blood.

15. Van Slyke, D. D., Hastings, A. B., Hiller, A., and Sendroy, J., Jr., J. Biol. Chem., 1928, lxxix, 769. Studies of Gas and Electrolyte Equilibria in Blood. XIV. The Amounts of Alkali Bound by Serum Albumin and Globulin.

16. Dill, D. B., Bock, A. V., van Caulaert, C., Fölling, A., Hurxthal, L. M., and Henderson, L. J., J. Biol. Chem., 1928, lxxviii, 191. Blood as a Physicochemical System. VII. The Composition and Respiratory Exchanges of Human Blood during Recovery from Pernicious Anemia.

17. Moss, K. N., Proc. Royal Soc. London, B, 1923-1924, xcv, 181. Some Effects of High Air Temperatures and Muscular Exertion upon Colliers.

18. Haldane, J. S., Brit. M. J., 1923, i, 986. Water Poisoning.

19. Hunt, E. H., J. Hygiene, 1912, xii, 479. The Regulation of Body Temperature in Extremes of Dry Heat.

20. Willcox, W. H., Brit. M. J., 1920, i, 392. The Nature, Prevention and Treatment of Heat Hyperpyrexia.

21. Gauss, H., and Meyer, K. A., Am. J. M. Sc., 1917, cliv, 554. Heat Stroke. Report of One Hundred and Fifty-Eight Cases from Cook County Hospital, Chicago.

22. Dill, D. B., Edwards, H. T., Bauer, P. S., and Levenson, E. J., Arbeitsphysiol., 1931, iv, 508. Physical Performance in Relation to External Temperature.

23. Moss, K. N., Tr. Inst. Min. Eng., 1923-1924, lxvi, 284. Some Effects of High Air Temperature upon the Miner.

24. Heller, H., and Smirk, F. H., J. Physiol., 1932, lxxvi, 1. Studies Concerning the Alimentary Absorption of Water and Tissue Hydration in Relation to Diuresis.

25. Oswald, R. J. W., Lancet, 1925, i, 1369. Saline Drink in Industrial Fatigue.

26. McCord, C. P., and Ferenbaugh, T. L., Mil. Surgeon, 1931, lxix, 608. Fatigue in Soldiers Due to Chloride Losses. Replacement through the Use of Sodium Chloride in Drinking Water. 